\title{
A bilingual dictionary for a specific user group: Supporting Setswana speakers in the production and reception of English
}

\author{
D.J. Prinsloo \\ Department of African Languages, University of Pretoria, Pretoria 0002, \\ South Africa \\ danie.prinsloo@up.ac.za
}

Ulrich Heid

Institut für maschinelle Sprachverarbeitung - Computerlinguistik.

Universität Stuttgart. Azenbergstrasse 12, D - 70174 Stuttgart, Germany and Department of African Languages, University of Pretoria, Pretoria 0002, South Africa

Ulrich.Heid@ims.uni-stuttgart.de

\begin{abstract}
The aim of this article is to discuss the design of a new English to Setswana dictionary for two narrowly defined target user groups of Setswana learners, i.e. Upper Primary (10 to 12 years old); and Junior Secondary ( 13 to 15 years old). The dictionary is intended to be a guide to text and speech production in the foreign language L2 (English) and the reception of English text and speech in L1 (Setswana). A general consideration concerns the relationship between the treatment of English and that of Setswana. As English is to be treated as a priority, many more data types will be made available for English than for Setswana. Furthermore, we will assess the possibility of producing a bilingual learners' dictionary with rather imbalanced parts: for production in (and translation into) English, a detailed description of individual items is needed, whereas for reception (and translation) from English, a large list of treatment units is necessary, albeit with less elaborate descriptive detail. The design also aims at strong guidance through the mother tongue, Setswana. Two possible scenarios are considered, namely separate dictionaries for the two target groups or a single dictionary to serve the lexicographic needs of both target groups. Socio-economic circumstances of most of the learners are such that buying more than one dictionary is not a realistic option, and they find themselves in a pre-dictionary culture with the resultant lack of dictionary using skills. The dictionary/dictionaries will be for paper dictionaries. The focus is on bilingualized (BLD) and extended bilingual (EBL) dictionaries as basic design options. We envisage an imbalanced design where guidance in terms of both production and reception is focused on English. Our design aims at the maximum utilization of the physical space in a paper dictionary with coverage of at least $90 \%$ of both English and Setswana.
\end{abstract}

\section{Introduction}

Modern lexicography is focused on the user perspective and aimed at the compilation of dictionaries according to the needs and dictionary using skills of well-defined target user groups. Gouws and Prinsloo (2005:39) in reference to Haas (1962), Barnhart (1962), Otto (1989) and Prinsloo and Gouws (1996) state it as follows:

Good dictionaries do not only display a linguistically sound treatment of a specific selection of lexical items. Good dictionaries are products that can be used as linguistic instruments by their respective target user groups. The better they can be used, the better dictionaries they are.

The aim of this article is to consider design options for a bilingual or bilingualized dictionary for languages L1 and L2 where the needs of a narrowly defined group of target users are limited to:

- text and speech production in L2, in the section of the dictionary where L2 is the target language

- text reception from L2 in the L2 to L1 section. 
The design of an English/Setswana dictionary is taken as a case in point. It will be shown how available treatment options could be maximally utilized in order to compile a dictionary with a limited macrostructure but a more extended microstructure in the L1 to L2 section, as opposed to a large macrostructure with limited microstructure in the L2 to L1 section. We expect this layout to be clearly adapted to the specific needs of the target user groups who are mother-tongue speakers of Setswana, to enable them to identify the data they are looking for in order to retrieve the necessary information and to utilize it in a productive (encoding) and receptive (decoding) way. Ideally, all the abovementioned designs and sub-designs should be built from an underlying multifunctional electronic data repository. Our data repositories include text and oral electronic corpora for both English and Setswana and they are mostly used for the generation of alphabetic and frequency word lists as well as for obtaining keywordsin-context (concordance lines). Word lists serve as the basis for lemma section and frequency indicators, and concordance lines are studied for sense distinction, collocations and examples of usage. The utilization of more advanced sources such as Word Sketches (Kilgarriff, Rychly, Smrz \& Tugwell, 2004) and the Database of ANalysed Texts of English (DANTE) (cf. Convery, Ó Mianáin, Ó Raghallaigh, Atkins, Kilgarriff \& Rundell, 2010), are also envisaged.

\section{Target user groups and their needs}

In this section, we summarize the intended user groups of the dictionary, as well as the needs the dictionary should cover. We make reference to the lexicographic function theory (Bergenholtz \& Tarp, 2002; Tarp, 2008) in terms of the parameters we contemplate.

The dictionary is intended for Setswana-speaking school children and young students from Botswana who seek empowerment in English. Two groups can be distinguished: Upper Primary level school children (aged 10 to 12 years) and Junior Secondary level (aged 13 to 15 years). As there is a marked tendency in the Botswana school system to favour the use of English, both user groups should essentially gain information about English from the dictionary.

Adeyemi (2008) states as follows:

In the Botswana context, bilingualism implies the provision of education to the citizenry through the medium of English, the official language, and Setswana, the national language.

The Botswana situation shows striking similarities to the one described by Kaalep and Jaan (2008:370) for Russian speakers living in Estonia, who find themselves in a socio-cultural/economic situation where 'knowledge of the Estonian language facilitates finding a job and promotion in a career'.

In terms of user needs, the dictionary should serve some of the main communicative needs of Setswana speakers, with respect to English, i.e.

- production of English texts and speech

- translation from Setswana into English

- reception of English texts and speech

- translation from English into Setswana.

These usage situations fall into two groups, one oriented towards the production of English (1/2) and the other towards the reception of English (3/4). The dictionary is to be instrumental in teaching the users the English language and making it accessible through Setswana. It is not intended to explain the Setswana language.

Given the user needs for the two target groups - several approaches should be considered. The first option is the use of standard monolingual English learner's dictionaries, e.g. the Macmillan English Dictionary for Advanced 
Learners (MEDAL) and the Chambers-Macmillan South African Dictionary Senior Primary (CMSAD) for the L2 needs, and the Setswana to English section of existing dictionaries for L1 to L2 look-up. This option entails buying and using two dictionaries which is not an option to most users. In addition, the currently available Setswana to English dictionaries do not provide sufficient support. In particular, many of them do not clearly distinguish target English equivalents of Setswana entry words. Consider (1)-(3) as extracts from the articles of setulo 'chair' in the available dictionaries.

(1) Setswana-English-Setswana Dictionary (SESD)

setulô N. CL. 7 se-, SING. OF ditulô, DER. F. dula, same as setilô [FOR.], a seat; chair; a stool.

(2) Dikišinare ya Setswana English Afrikaans Dictionary (DS)

túlō (tulô), di- dev < dula, place, dwelling // plek, tuiste; se- di-, chair // stoel

(3) Secwana-English Dictionary (SED)

setulò n., ditulò, from dula; A seat; a chair; a stool.

The second basic option is a bilingualized dictionary L2-L2-L1 where existing monolingual English learner's dictionaries could be supplemented with an L1-L2 section. The third option could be tailor-made (extended) bilingual dictionaries for the respective target user groups or a single dictionary for use by both groups.

\section{The bilingualized dictionary}

The basic design of a BLD is L2-L2-L1 where L2 is the foreign language, e.g. L2 (English lemma) - L2 (English definitions, examples, etc.) - L1 (Setswana equivalent). The amount of L2 information given in the 'monolingual' section and the number and extent of translations into L1 vary. Thumb (2002) distinguishes between partial and full bilingualization depending on the amount of L2 text translated into L1. Some bilingualized dictionaries are mono-directional i.e. they consist solely of a L2-L2-L1 section without an L1-L2 index/section. Even in cases where an L1-L2 section is provided, a huge imbalance in terms of page allocation exists, estimated by Pujol, Corrius and Masnou (2006:198) at a 84\%:16\% division.

A detailed analysis of arguments for and against the use of monolingual, bilingual and bilingualized dictionaries falls beyond the scope of this article, but the interested reader is referred to Thumb (2002) who summarizes different opinions. In this article the bilingualized dictionaries will only be discussed with regard to their suitability as a design model for our intended dictionaries.

It should be stated at the outset that the value of bilingualized dictionaries in foreign language learning is not disputed in the literature. It is generally accepted that bilingualized dictionaries have merit. Laufer and LevitzkyAviad (2006:137) summarize general views stating that 'the strength of the bilingualised dictionary lies in its catering for a variety of look up possibilities and personal preferences, and in combining monolingual and bilingual information'. Nakamoto (1994:7-8) as quoted by Thumb (2002:34, 35 \& 37) cited a number of disadvantages of monolingual and bilingual dictionaries and six advantages of bilingualized dictionaries:

1. L1 translation equivalent supplements the L2 definition when the user is unsure of its meaning.

2. L1 translation equivalent corrects a misconception when the user misunderstands the L2 definition.

3. L1 translation equivalent reinforces user's understanding of L2 lexical item and assures retrieval of correct meaning.

4. L1 translation equivalent dispels the frustration that is formed by the user's psychological need to know the L1 translation.

5. The user will be prevented from reinforcing the equation of one to one equivalence between L1 and L2. 
6. All types of users can have access to the same original monolingual dictionary e.g. Japanese learners of English and Hebrew learners of English can each use a bilingualized version of the same monolingual learner's dictionary (see also Tomaszczyk, 1983:43, 45).

BLDs are however criticized for what Laufer and Levitzky-Aviad (2006:137) call a weakness of 'unidirectionality', and this is particularly problematic when the learner needs to find an unfamiliar L2 word for a familiar L1 concept. This is where strong L1-L2 guidance is essential and where most L1-L2 dictionaries fail to such an extent that learners fall back on their L2-L1 bilingual dictionaries instead.

Surveys of dictionary use indicate that the majority of foreign language learners prefer bilingual L2-L1 dictionaries and use them mainly to find the meaning of unknown foreign (L2) words (Atkins 1985, Piotrowsky 1989). However, if learners writing in L2 need an L2 word designating a familiar L1 concept, they do not readily turn to an L1-L2 dictionary for help. The reason for this may lie in a serious limitation of most L1-L2 bilingual dictionaries. They rarely differentiate between the possible L2 translations of the L1 word, nor do they provide information regarding the use of each translation option (Laufer \& Levitzky-Aviad, 2006:137).

Compare (1) to (3) in this regard as typical examples of insufficient discrimination between the L2 translations.

The most compelling argument for the indispensability of bilingual dictionaries is that, while a monolingual dictionary of L2 can, to some extent, substitute for a bilingual L2-L1 one, there is no lexicographic alternative to an L1-L2 dictionary. In a situation when a foreign learner wants to say or write something in L2, but does not know the word(s) for (part of) what they intend to talk about, L1 provides the easiest - often the only - kind of access to the foreign language code. If one has no idea what $\mathrm{L} 2$ item(s) to look up in the first place, the monolingual $\mathrm{L} 2$ dictionary remains a locked treasure chest to which one does not have the key (Adamska-Sałaciak, 2006:24/25).

This is a crucial aspect for our design, especially when teachers instruct learners to write in L2 while giving the instruction in L1. The issue of the nature and amount of guidance in respect of L1 is central in the compilation of bilingual dictionaries but also in the L2-L2-L1 and L1-L2 sections of BLDs. Considerations should be extended beyond mere typical shortcomings such as an inadequate distinction between translation equivalents, to the role of guiding and facilitating the productive use of a foreign language through the mother tongue. The latter aspect, as will be indicated below, is of specific relevance to our younger target user group.

\section{Integration of the mother tongue}

The issue here is to what extent the advantage of mother-tongue knowledge should be utilized in foreign language production. General views vary from not at all to maximal utilization in terms of production via the mother tongue. Marello (1998:292/293) points out that lexicographers such as Hornby are firmly committed to the pedagogical principle that English should be learned through the medium of English. They are unwilling to accept that the learners' mother tongue could be used for the initial presentation of meaning. Adamska-Sałaciak (2006:23) quotes Atkins (1985:22) in stating that 'teachers prefer monolinguals for their long-term benefits: the user gradually learns to operate in L2 without the L1 barrier as a brake in progress'. We however agree with Adamska-Sałaciak (2006:23) that such a statement should be supported by empirical evidence and that it has hitherto probably just been taken for granted.

Pujol et al. (2006:197) acknowledge the value of bilingualized learners' dictionaries because they provide users with access to both monolingual and bilingual information. They, however, state a major objection against printed bilingualized dictionaries namely that users tend to skip the monolingual part and read only the L1 text, thus missing exposure to L2. They therefore propose the concept of 'print deferred bilingualized dictionaries' where the L1 translations are relocated to a position elsewhere in the dictionary as in Figure 1 where the translation equivalents 
for nap, i.e. becaina and migdiada are given as reference addresses of the numbers 3580/590 in the reference position within the article of nap.

Figure 1: Deferred translation equivalents for nap

First part (L2)

$\mathrm{L} 2 \rightarrow \mathrm{L} 1$

Second part $(\mathrm{L} 1 \rightarrow \mathrm{L} 2)$

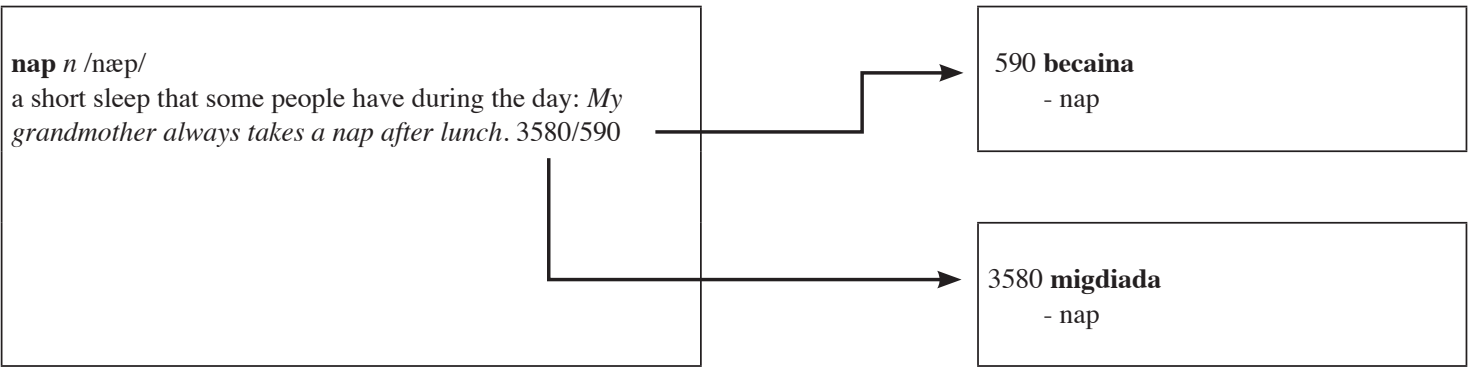

(Pujol et al., 2006:207)

This approach is exactly the opposite of what we wish to obtain - i.e. stronger linkage and identification with the L1 equivalent rather than enforcing increased utilization of the L2 monolingual data. Furthermore the claim that users tend to give less attention to the monolingual part makes the bilingualized option less attractive for our needs. Exposure to the L2 monolingual part is essential for text production in English for the Setswana learners, but mother-tongue linkage should rather be strengthened than weakened. Atkins and Rundell (2008:40) formulate this in plain English:

The SL speakers need all the help they can get. Don't short-change them. They're trying to write in a foreign language. The TL speakers can wing it if the worst comes to the worst. They're writing in their own language - as long as they can understand what the foreign word means, they'll manage.

Kernerman (2000:825) also acknowledges the value of the integration of the mother tongue and formulates it as follows:

... dictionaries for production are becoming more prevalent, and integration of the mother tongue, a vital factor in foreign language learning, is now becoming an important feature in many learners' dictionaries, which were hitherto strictly monolingual.

Tarp (2008) discusses this issue in detail, especially by correlating the learning process and the L2 skills over time with the amount of consultation of lexicographic data via the mother tongue and/or via the foreign language (2008:149-151). And he concludes as follows:

[...] traditional learner's dictionaries that are either monolingual or bilingual only have a limited useful value. Traditional bilingual learner's dictionaries may be sufficient for learners who are beginners, and traditional monolingual learner's dictionaries may be sufficient for very advanced learners. But for the vast majority of intermediate learners located between these two extremes neither a monolingual nor a bilingual learner's dictionary will be sufficient in itself, since these learners need either both types of dictionary or a dictionary offering a total solution combining the characteristics of the two dictionary types: a bilingual approach via the mother tongue, and an approach based on the foreign language whether it is monolingual or bilingual, leading back to the mother tongue (Tarp, 2008:151).

As we think that our user groups are indeed of the intermediate type evoked by Tarp, an objective of the design study presented in this article is to explore presentational devices which combine characteristics from both traditional types of learner's dictionaries. 
Tarp's proposals have a number of implications on both levels of lexicographic work, that of the description of the language data (Atkins, 1985: pre-lexicography, Bergenholtz \& Tarp, 2002: 'data base') and that of lexicographic data selection, ordering and presentation (Atkins, 1985: lexicography, Bergenholtz \& Tarp, 2002: dictionaries), i.e. on the levels of the selection of lexicographic data (what to describe?) of the data distribution, and of the design of access routes to the data. We will discuss and illustrate these implications in greater detail below, but a few general principles need to be mentioned first.

Tarp (2008:59) says that 'the production of foreign-language texts can take place based either on thinking directly in a foreign language or on prior thinking, in a mother tongue':

...the process in connection with thinking via the mother tongue consists of two sub-stages requiring different lexicographical treatment: transferring the text to the foreign language, and subsequent production in the foreign language. Production in the foreign language may thus give rise to problems on three different levels requiring different types of lexicographical treatment:

1) production of text in a foreign language thinking via mother tongue

a) transfer from mother tongue into foreign language

b) production in foreign language (in a narrow sense)

2) production of text in foreign language thinking via the foreign language

Even in the case of text reception, Tarp (2008:60) in reference to Hausmann (1977), states that the reception of foreign language texts takes place either within the foreign language concerned or via the mother tongue.

\section{The proficiency factor: dictionary using skills and the weaker student}

Marello (1998:309), in reference to Atkins and Varantola (1997), states that monolingual dictionaries are referred to more often by users with advanced L2 skills while bilingual dictionaries remain the type most often used by beginners and intermediate students. Laufer and Melamed, as quoted by Marello (1998:309), concluded from performance results obtained by users of different types of dictionaries that the best results were obtained from the use of bilingualized dictionaries for production purposes by good and average users. They report, however, that unskilled users did better when presented with a bilingual dictionary. This observation is important to our approach and design decisions since many of our younger group of target users in particular, are either unfamiliar with dictionary use or are amongst the weaker students or both.

\section{The extended bilingual dictionary}

An extended bilingual dictionary (henceforth EBL), is an alternative to the bilingualized option for our intended dictionary for $\mathrm{L} 2$ production and reception purposes.

The main task of a bilingual dictionary is to provide help in negotiating meaning between two languages by means of providing translation equivalents L1-L2 and vice versa. In the case of a Setswana-English dictionary, interlingual anisomorphism (cf. Adamska-Sałaciak, 2006:24) is a major problem. Numerous cases of zero-equivalence, on lexical as well as conceptual level exist but, according to Adamska-Sałaciak (2006:24), "bilingual dictionaries have to try and do their job despite the fact that the lexicons of natural languages are resistant to pairwise matching'.

We believe that a core element of an EBL should be guidance through the mother tongue and sound implementation of what Bogaards and Hannay (2004:464) refer to as 'the riches of the modern learners' dictionary to a well organized set of data concerning the L1 of the learners'. This is done by giving 'the very rich data that are available in the L2 learners' dictionary' as treatment of the L1 lemmas in the L1-L2 section of the dictionary. 
Rundell (2008:222) mentions that this 'richness' entails a number of important aspects i.e. vocabulary control, grammatical and syntactic information, the role of examples and phraseology, as key elements of the features required from dictionaries to fulfil the needs of non-native learners of English. He emphasizes that improvement (of monolingual dictionaries) - for our design interpreted in a wider context - can be said to take place when:

- the description of a language that a dictionary provides corresponds more closely to reliable empirical evidence regarding the way in which that language is actually used

- the presentation of this description corresponds more closely to what we know about the reference needs and the reference skills of the target user [original emphasis].

Rundell (2008:230), in reference to Atkins (1992/3), also states that the lexicographer's task should be performed in two stages, namely, an analysis process and a subsequent process of synthesis. The former entails the collection of all relevant facts regarding the word and the latter process extracts the relevant facts for the particular dictionary being compiled.

Laufer and Levitzky-Aviad (2006:135-139) refer to their design of a bilingual dictionary for production as 'Bilingual Dictionary Plus'. They suggest that articles in such a dictionary should include the following four elements:

- L1-L2 translations

- L2 information (definitions, examples, etc.) about each translation option

- Thesaurus-like information, i.e. semantically related words to each translation option

- Additional L1 meanings of the L2 translations.

Consider the following example reflecting these four features and note the application of additional L1 meanings of the L2 translations under 'other meanings':

find out (vt, past tense, past participle found out)

ברר (BERER)

to learn something by study or inquiry: Find out the cost and let me know.

Please find out when the next train leaves.

Related words:

get at ( $\mathrm{v}$ prep, infml) to manage to find out

גילה (GILA)

I'm afraid we just can't get at the information; no one will help us.

determine (vt, fml) to find out exactly: חישב וקבע (CHISHEV VE-KAVA)

The police wanted to determine all the facts/what happened.

detect (vt, fml \& tech) to find out:

הבחין (HIVCHIN)

We have been able to detect some improvement as a result of the medicine.

Other meanings of find out:

ידע על כר. You've broken the vase and if your mother finds out she'll be angry

(YADA AL KACH)

Don't steal pens; if you're found out there'll be trouble. תפס (TAFAS)

(Laufer \& Levitzky-Aviad, 2006:140)

We aim to provide users with a rich L2 (English) macrostructure for decoding purposes i.e. to find the meaning of L2 words. Laufer and Levitzky-Aviad (2006:135), in reference to Aust, Kelley and Roby (1993), link the prefer- 
ence for L2-L1 dictionaries to the 'users' desire and need to gain immediate understanding of the material they are reading' (our emphasis). To avoid user-frustration by not finding the L2 words in the dictionary, the L2 macrostructure needs to be large, containing the English words most likely to be looked up. For our approach, this means having a large macrostructure with sufficient guidance for the users to get the applicable translation equivalent(s) in L1 to understand the meaning of the L2 word. For looking up a L1 word with a view to text and speech production with the L2 equivalent, strong guidance and an elaborate microstructure is envisaged. Assistance should include guidance via the mother tongue and clear L2 sense distinctions - especially for the younger target users. For our purposes, the treatment of the lemma find out is quite appealing, but more syntactic guidance will be given.

Support for an imbalanced design in respect of a large macrostructure (a large number of entries) and a relatively limited microstructure for the L2-L1 section and a very detailed microstructure with limited macrostructure in the L1-L2 section is found in the view of Marello in reference to reading versus writing activities:

The macrostructure of such a bilingual dictionary is differently organized in the two sections. The section L2-L1 is meant for native speakers of the L1 wishing to read texts in the L2 and is therefore larger ... than the L1-L2 macrostructure, which is mainly meant for the user wishing to write texts in the L2. As a consequence L1-L2 microstructures are generally more detailed and richer in grammar than L2-L1 microstructures (Marello 1989). This is one of the chief respects in which a true bilingual dictionary differs from a BLD (Marello, 1998:294).

\section{Macrostructural considerations L1-L2 and L2-L1 sections}

A relatively small macrostructure for L1-L2 and a large macrostructure for L2-L1, were fundamental to all of the design options that we considered. The aim of the dictionary is an approximate 90-95\% coverage of English and Setswana (10,000 Setswana lemmas, versus 15,000 English lemmas), but the impact of the reduced lemmalist for Setswana in terms of coverage was a point of concern. The question was whether a lemmalist of 10,000 lemmas would be sufficient for the envisaged 90\% coverage of Setswana. In COBUILD (preface), it is estimated that the top 14,700 lemmas (indicated by frequency bands in the form of black diamonds) cover $95 \%$ of 'all written and spoken English'. Setswana corpus evidence suggests that $90.5 \%$ coverage is obtained by the top 10,000 lemmas (cf. Prinsloo, 2006). This represents added value for the new design as a 33\% difference in the size of the macrostructures of the two sections still renders coverage in excess of $90 \%$.

The calculations in terms of space allocation applicable to both approaches are made by following the typical pageallocation breakdown in bilingualized dictionaries; $80 \%$, that is 800 pages from the available circa 1,000 pages are allocated to the L2-L2-L1 section and 20\%, i.e. 200 pages for the L1-L2 section. For a bilingual, dictionary the division in terms of physical space would be 50:50, i.e. 500 pages for each section. A 50:50 balance is possible because the larger macrostructure (higher number of entries) with a relatively less-detailed microstructure in the L2-L1 section is balanced out by a smaller macrostructure (less entries) with a more detailed microstructure in the L1-L2 section of the dictionary.

To ensure a proper balance between alphabetical stretches, the Setswana Ruler and Block System designed in Prinsloo (2004) and a Ruler for English (Prinsloo \& De Schryver, 2005) were used. These tools are described in detail in Prinsloo and De Schryver (2002, 2003 \& 2005). Lexicographic Rulers can briefly be described as practical instruments of measurement for the relative length of alphabetical stretches in alphabetically ordered dictionaries. 
Figure 2: A ruler for Setswana

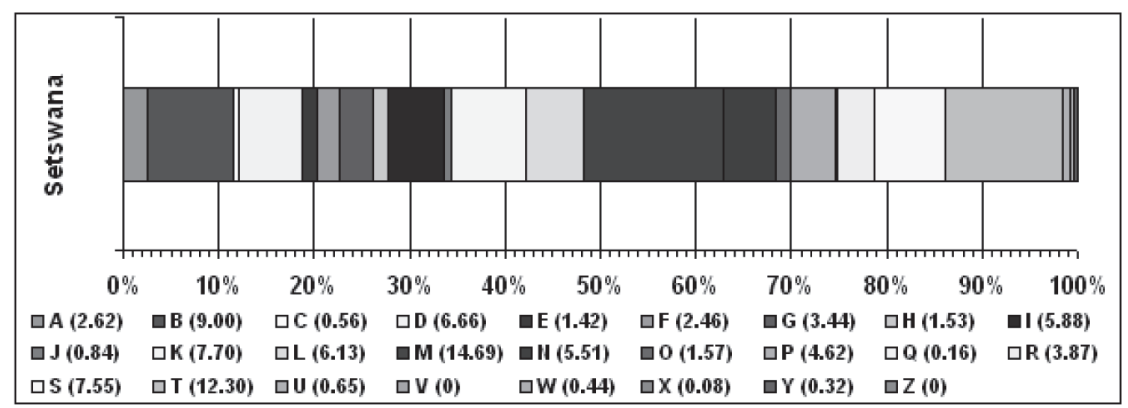

Figure 3: A ruler for English

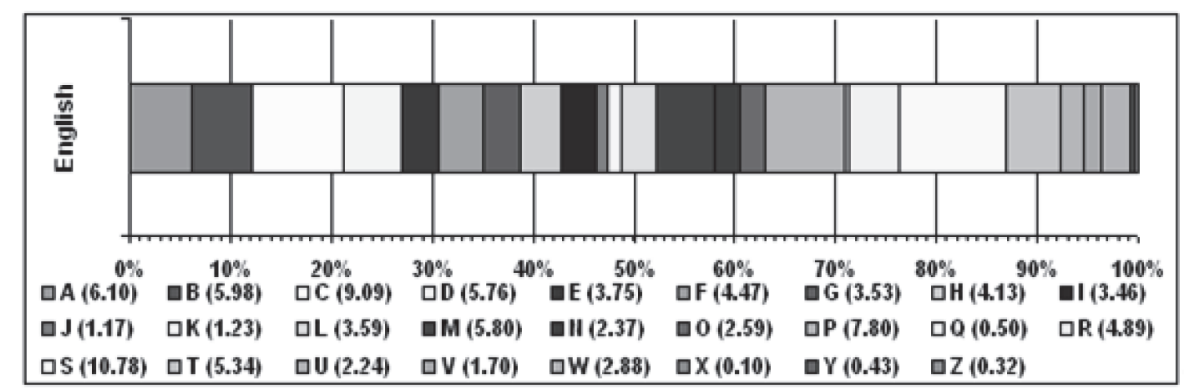

The Setswana Block System given in the Appendix, represents a breakdown of this ruler into 100 blocks (i.e. each reflecting a sub-stretch equal to $1 \%$ of the task) which is used for the actual pacing of the compilation process in terms of sub-stretch to be covered, time utilized for the compilation of the dictionary, etc.

\section{Microstructural considerations L1-L2 and L2-L1 sections}

On the microstructure level, two approaches were considered i.e. a BLD and an EBL. In each case, consideration was given to the distinction between the Upper Primary and the Junior Secondary group or an adapted design if the publisher would insist on a single dictionary to serve the lexicographic needs of both of these user groups. In the following subsections, we will first explain some of the data we use as examples in the entries which we will discuss below; the data are supposed to illustrate different linguistic phenomena which need to be adequately presented in the dictionary.

To exemplify our proposal for a dictionary design, we use a subset of the vocabulary of sitting and seats. In fact, relevant English items include, among others, those given in (4). For Setswana, we analyse the items indicated in (5).

(4) chair, n., chair, v., seat, n., stool, n., sofa, n., bench, n., sit, v.

(5) setulo/ditulo, n. 7/8; setilo/ditilo, sepora (traditional term) n. 7/8; sedulo/didulo, n. 7/8; senno/dinno, n. 7/8; tulo/ditulo, n. 9/10; bodulo/madulo, n. 14/6; bonno/manno, n. 14/6; dula, v.; nna, v.

\section{Readings and intralingual relationships}

The English items chair, n. and seat, n. are partial synonyms in their readings 'piece of furniture to sit on'; they are obviously not synonymous in their other readings, cf. (6) and ( $\left.7^{1}\right)$; the synonymy is partial, as 'seat (a)' is more general:

(6) chair, n.

(a) piece of furniture to sit on, (b) person in charge of a meeting, (c) position in a university, (d) electric chair

(7) seat, n.
(a) something to sit on,
(b) place in a vehicle or theatre, 
(c) place in parliament or on a committee,

(d) main place, main building, headquarters,

(e) part of the body on which a person sits [formal]

There is clearly a quasi-synonymy relation also between 'chair (b)' and 'chairperson', 'chairman', 'chairwoman', and a class $\leftrightarrow$ individual relationship between 'chair (b)', 'chairperson' etc. and 'chairmanship'. Moreover, 'chair (a)', and 'stool (a)', 'bench (a)' and 'sofa' are cohyponyms, i.e. all are pieces of furniture to sit on. As most English learner's dictionaries use 'seat (a)' to define these items, 'seat (a)' can be taken as their hyponym, cf. (8a), (9a) and (10).

(8) stool, n.

(a) seat with legs, but no back and arm support, (b) solid waste from somebody's body

(9) bench, n.

(a) hard seat for two or more people, (b) long table for work with tools

(10) sofa, n.

large soft seat for two or more people

Setswana has several synonymous words for chair (a/c) and seat (a). These are setulo, sedulo, setilo, senno. Moreover, it has overlapping readings of bonno/manno and tulo/ditulo, when it comes to the reading 'place to stay', 'habitat'. For the sake of simplification, we give approximate paraphrases of bonno and tulo in English, in (11) and (12) with their respective nominal class numbers given in brackets.

(11) bonno/manno, n (14/6)

(a) place (to stay), (b) habitat

(12) tulo/ditulo, $\mathrm{n}(9 / 10)$

(a) place to stay, (b) habitat, (c) dwelling

Obviously, all of setulo, setilo, sedulo, tulo, bodulo are related and derived from the verb dula ('sit'); and senno, as well as bonno are derived from the verb $n n a$, which is synonymous with dula. The class $14 / 6$ nouns bodulo and bonno are more abstract than the class $7 / 8$ nouns setulo etc., cf. (13) for the readings of bodulo.

(13) bodulo/madulo, n (14/6)

(a) sitting place, room, seat (of any kind): bodulo kwa holong (a seat there in the hall)

(b) sitting room, lounge

(c) position (of a king, ...): ... ka fa bodulo jwa me jwa bogosi bo phalang bodulo jwa gago jwa boruti (how my position of kingship supersedes your position of religion)

A contrastive comparison of Setswana and English is only possible on the basis of readings, and we use those summarized above as an example. In the following, we will discuss and graphically display the equivalence relations. This pairing of languages is similar to the backbone of a bilingual dictionary framework (cf. Atkins \& Grundy, 2006).

The Setswana synonyms setulo, setilo, sedulo and senno are all related with 'seat (a)' and 'chair (a)'. They also share partial equivalence with 'bench (a)', 'stool (a)' and 'sofa', as Setswana has no specific single lexemes for these; Setswana has, however, sofa as a loan word. This situation is depicted by Figure 4, below. 
Figure 4: Equivalence relations between English and Setswana of words for pieces of furniture

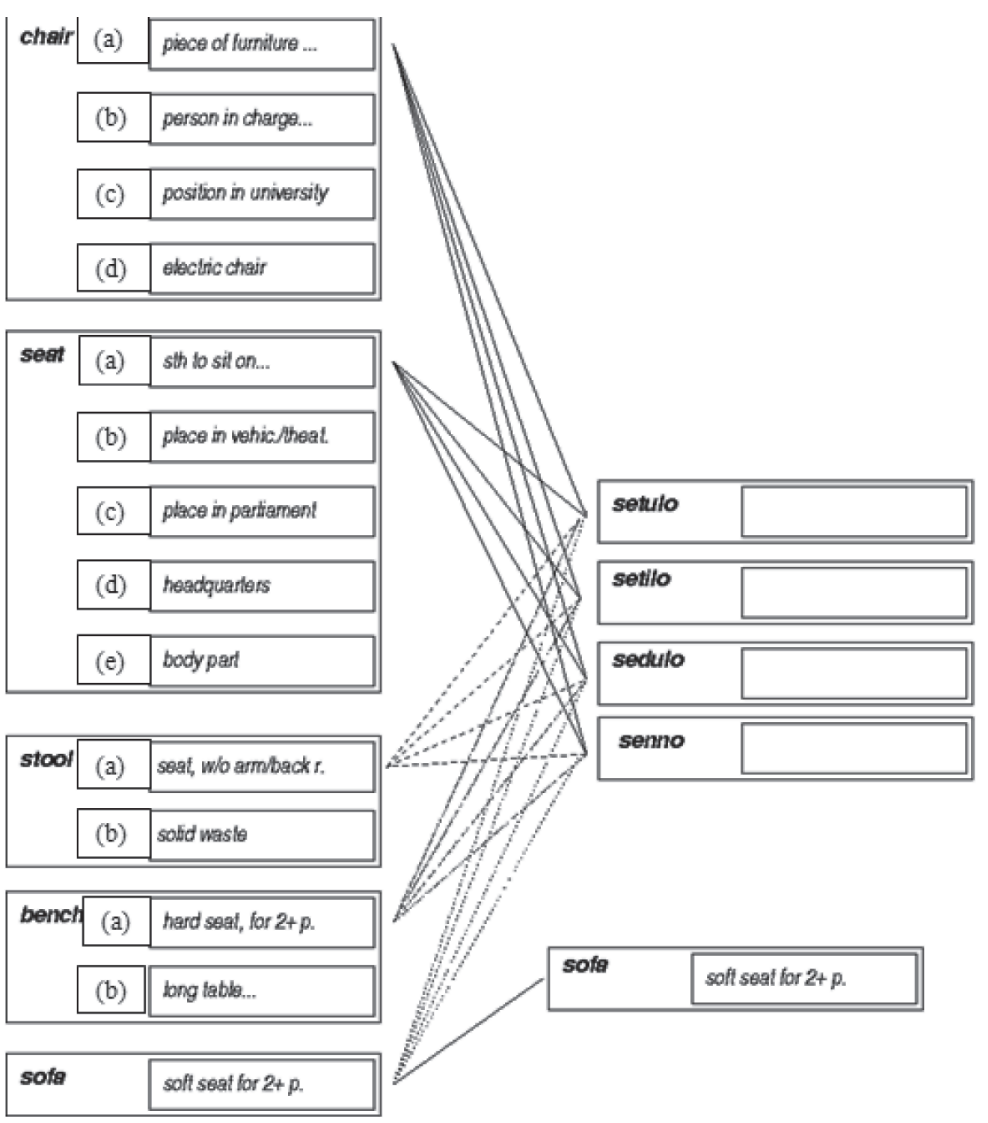

Setswana has two words for the chairing function of a person ('chair (b)' in (6)), namely modulasetulo and modulasetilo. Furthermore, there are words for chairmanship, namely bodulasetulo and bodulasetilo. Figure 5 shows these relationships, as well as those for 'chair (c)'.

Figure 5: Relationships between modulasetulo/modulasetilo and chair

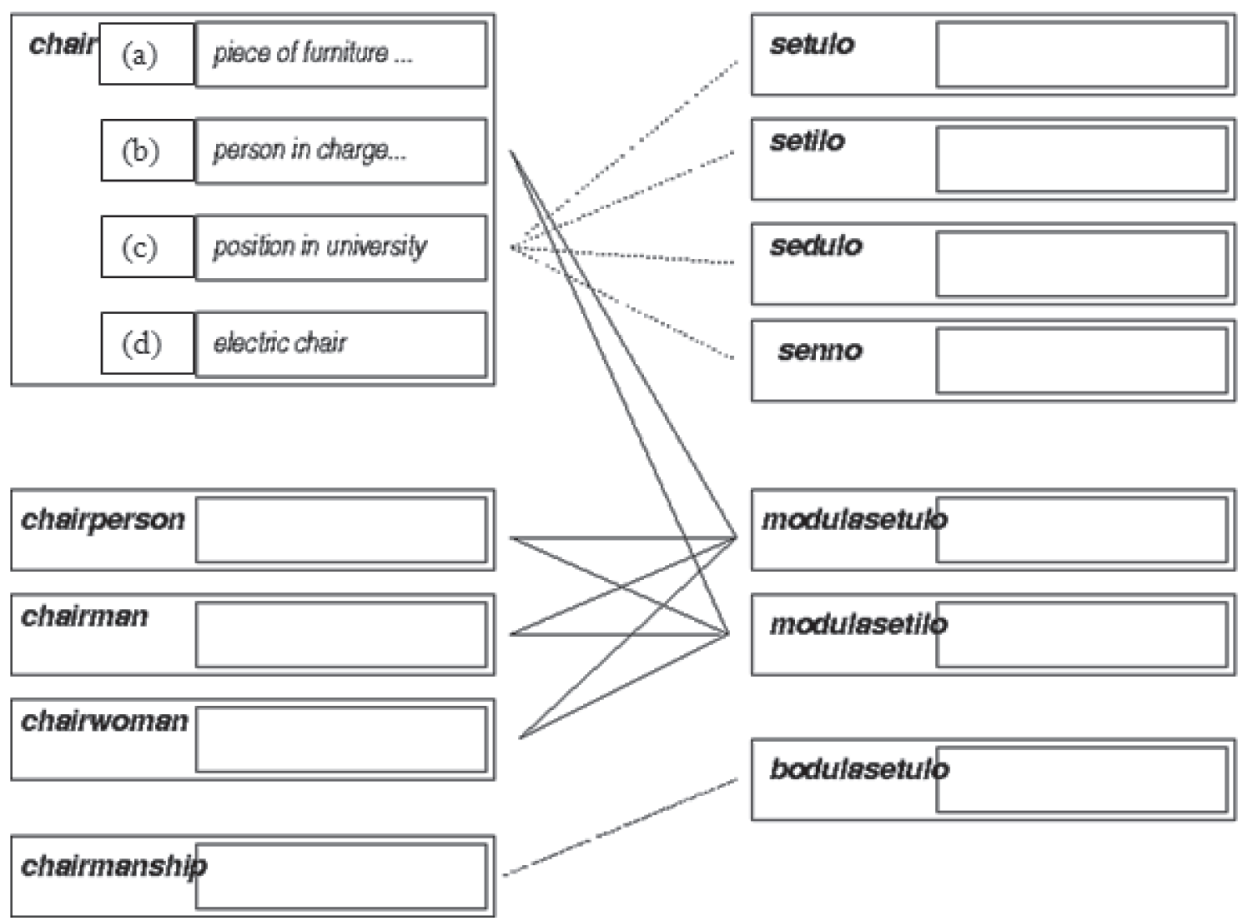


The broader picture of nominal equivalents between Setswana and English, for the fragment described above, is summarized in Figure 6.

Figure 6: Network of equivalents between English and Setswana for 'chair', 'seat', etc.

\section{CHAIR}

Piece of furniture to sit on

Person in charge of a meeting

(Teaching) position, e.g. school/college/university

Electric chair

SEAT

Something to sit on

Place in vehicle or theatre

Place in parliament

Main place, headquarter

Body part

$\mathrm{BENCH}$

STOOL

Seat without armrest or back

Solid waste from body

SOFA

CHAIRPERSON, CHAIRWOMAN

CHAIRMANSHIP

POSITION

Social position

...

PLACE

Place to stay

(abstract) place in someone's heart

HABITAT

SITTING ROOM, LOUNGE

OPENING, VACANCY, OPEN POST
SETULO, SETILO, SEDULO, SENNO

piece of furniture to sit on

Modulasetulo

Setulo sa borutabana

Thapo, setulo sa motlakase

BODULO

Bodulo (ka mo sejanageng/teatareng)

bodulo ka mo palamenteng

Kantorokgolo

MARAGO

MASEPA, MANTLE

SOFA

MODULASETULO, MODULASETI-

LO, MOTSHWARAMARAPO

BODULASETULO, BODULASETILO

MAEMO, BODULO

Maemo

Tulo

lerato la pelo

PHATLATIRO 


\section{An EBL approach}

This second design option for the dictionary is thus to have two imbalanced halves, one for production (L1-L2 (Setswana-English)) and one for the reception of English (L2-L1 (English-Setswana)). Once again, a single dictionary could be designed catering for the needs of both user groups, or two separate dictionaries could be designed catering for the Upper Primary and Junior Secondary groups. It could be argued that the users' age difference correlates with a difference in their English language proficiency level.

As younger children will prefer access to data about English via their mother tongue, they should be guided through the English definitions by means of Setswana. The nature and amount of guidance for the more versus the less advanced target groups should however, be carefully considered as the more advanced learners may profit more (for the enhancement of their English language skills) from a complete exposure to the foreign language (i.e. English) material.

The English to Setswana section provides a broad inventory of English items described for receptive purposes. The Setswana to English section uses Setswana as an access route to English whilst the English to Setswana section uses Setswana as an additional checking and confirmation tool for users who want to understand English. Equivalence relationships are expressed on the basis of readings of lexemes - we indicate these with short explanations. To ease the consultation of the dictionary, we avoid nesting and the treatment of derivational relationships by means of subentries.

While retaining the principle of a mixed mono-/bilingual learner's dictionary, we distinguish two approaches related to our two user groups:

- For the younger users (less advanced), a translation-like approach is followed which presents, for example, sense distinctions in Setswana.

- The advanced intermediate users are encouraged to go from the Setswana entry directly to a microstructure, which is essentially English, to help train them to eventually use a monolingual English learner's dictionary.

To illustrate the differences between the two sides of the dictionary, as far as the lemmalist goes, we present the relevant lemma inventory of the receptive part (17) and of the productive part (18) below. Note that the distinction between younger and more advanced users may also influence the lemmalists, but for now, we assume that it does not.

(17) bench, chair, chair lift, chairman, chairmanship, chairperson, chairwoman, habitat, lounge, opening, place, position, post, seat, sitting room, sofa, stool, vacancy

(18) bodulasetulo, bodulo, bonno, didulo ( $\rightarrow$ sedulo $>$ setulo), dinno ( $\rightarrow$ bonno), ditilo ( $\rightarrow$ setilo $>$ setulo), ditulo ( $\rightarrow$ tulo, $>$ setulo), madulo $(\rightarrow$ bodulo), manno $(\rightarrow$ bonno), marago, masepa, mantle, modulasetilo $(\rightarrow$ modulasetulo), modulasetulo, sedulo ( $>$ setulo), senno ( $>$ setulo), setilo ( $>$ setulo), setulo, sofa, tulo

In (18), we use the listing to illustrate a double cross referencing system used in the Setswana to English part using the reference marker ' $\rightarrow$ '. As it is done, for example, in $O N S D$ for Sepedi to English, we lemmatize both singular and plural forms of nouns. Contrary to $O N S D$, we do not lemmatize locatives. The entries of plurals usually are just cross reference entries, pointing to the singular forms.

As we deal with a number of synonymous variants (e.g. sedulo/setulo/setilo/senno), we also introduce a system of synonymic cross references indicated by ' $\boldsymbol{\nu}$ '. In the proposed printed version, these point from lesser used variants to predominant, frequent ones, e.g. in the case of sedulo etc. to setulo. In the underlying data collection, we prefer to have more information, i.e. relationships between all synonyms, and a marking of the preferred one. This allows 
us to generate cross-references for different purposes and helps avoid a loss of information in a situation where e.g. low frequency items are not mentioned in a particular dictionary version at all.

Obviously, a similar system of synonymic (and even quasi-synonymic) relationships can also be introduced for the English part of the dictionary.

In the lemmalists of both sections we will use three layers of filled or unfilled circles $\bigcirc$ and $\bullet$, to indicate high frequency zones, i.e. $\bullet \bullet, \bullet \bullet$ and $\bigcirc \bigcirc$ respectively. Similar marking systems have been used to indicate frequency zones for English in COBUILD or in ONSD for Sepedi.

On a more intuitive basis, we also apply the frequency criterion to the selection from the readings summarized in Figure 6.

\section{Microstructure of the production-oriented part}

The entries of the production-oriented part of the dictionary (Setswana to English) consist of a number of components (types of lexicographic data, indications), which are summarized as follows:

- lemma (Setswana)

- part of speech (and noun class) of lemma

- reading/sense indicators $(1,2,3, \ldots \mathrm{a}, \mathrm{b}, \mathrm{c}, \ldots)$

- meaning explanation or gloss or sense label, as provided e.g. in the MWB or LDOCE dictionaries.

- equivalent or set of (quasi-) synonymous equivalents (English)

- collocations of each equivalent, presented in the form of short, typical sentences (or chunks) and their translations (tsaya setulo 'take a chair')

If the abovementioned inventory of lexicographic data types is used throughout the production-oriented entries, we nevertheless distinguish two ways of presenting these lexicographic data types depending on the age and knowledge of the users. For the Upper Primary users, we make all data accessible through Setswana, their mother tongue. In other words, both the lemma and the meaning explanations are in Setswana; we present the collocations and example sentences by first printing the Setswana version, and thereafter the English one. A sample entry for setulo is given in (19).

(19) setulo noun $7 / 8$

1 fenitšhara mo go dulwang mo go yone

(a) ya tlwaelo: chair, seat

- dula mo setulong se tsweetswee: sit in this chair, please; take this seat, please

- a tsaya setulo a se baya mo pele ga sofa: he then took the chair and put it in front of the sofa

- a goga setulo, a nna mo fatshe: he then pulled out a chair and sat down

(b) sa go tlhoka matsogo le matshwaro/maitshegetso a morago: stool

$\checkmark$ o dutse setulong mo bareng: he sat on a stool in the bar

(c) banka se se thata mo go dulwang batho ba babedi kgotsa go feta: bench

- ba dutse mmogo setulong: they sat together on the bench

(d) setulo se se boleta mo go dulwang batho ba babedi kgotsa go feta: sofa

$\checkmark$ e bile a nwetse mo setulong sa sofa: he relaxed on the sofa-chair

2 maemo a a kwa godimo a thuto, boporofesara kwa Yunibesithing

$\checkmark$ o ne a kotame setulo sa boporofesara ba Setswana kwa Yunibesithing: he held the Chair of Setswana at the University

We choose another presentation for the advanced intermediate learners. As they supposedly have more knowledge of English, they should be able to produce English texts without constant reliance on translations from Setswana, 
and be able to handle a dictionary which is similar in its structure to a monolingual English learner's dictionary. Nevertheless, they may sometimes need to verify their hypotheses about English against translations to Setswana, and they need access to the English data via Setswana lemmas. Consequently, we order the lexicographic data types mentioned above in such a way as to provide the English meaning explanations, and collocations and examples where the English is first mentioned, then a Setswana translation. Figure 5 contains the same entry, s.v. setulo, in the version for advanced users.

(20) setulo noun $7 / 8$

1 furniture to sit on

(a) chair, seat

$\checkmark$ sit in this chair, please: dula mo setulong se tsweetswee

$\checkmark$ take this seat: dula mo setulong se

- have a seat, please: dula mo tsweetswee; nna mo fatshe tsweetswee

$\checkmark$ take this seat (away)!: tsaya setulo se!

(b) stool (without a backrest or armrest)

- he sat on a stool in the bar: o dutse mo setulong kwa bareng

(c) bench (hard chair for more than one person)

$\checkmark$ they sat together on the bench: ba dutse mmogo mo setulong

(d) sofa (soft chair for more than one person)

- he relaxed on the sofa-chair: $\mathrm{e}$ bile a nwetse mo setulong sa sofa

2 academic position, professorship at a university

- he held the Chair of Setswana at the University: o ne a kotame setulo sa boporofesara ba Setswana kwa Yunibesithing

Should the publisher insist on the compilation of a single dictionary, i.e. one dictionary for both target groups, (19) and (20) can be combined as in (21):

(21) setulo noun $7 / 8$

1 fenitšhara mo go dulwang mo go yone furniture to sit on

(a) chair, seat

$\checkmark$ sit in this chair (have a seat), please: dula mo setulong se tsweetswee

$\checkmark$ take this seat: dula mo setulong se

$\checkmark$ take this seat (away)!: tsaya setulo!

- have a seat, please: dula mo setulong tsweetswee; nna mo fatshe tsweetswee

(b) stool (without a backrest or armrest)

- he sat on a stool in the bar: o dutse mo setulong kwa bareng

(c) bench (hard chair for more than one person)

$\checkmark$ they sat together on the bench: ba dutse mmogo mo setulong

(d) sofa (soft chair for more than one person)

- he relaxed on the sofa-chair: e bile a nwetse mo setulong sa sofa

2 maemo a godimo a thuto, boporofesara Yunibesithing academic position, professorship at a university

- he held the Chair of Setswana at the University: o ne a kotame setulo sa boporofesara ba Setswana kwa Yunibesithing

This design is even closer to a fully bilingualized dictionary because extended translated sense labels are given which can even be interpreted as abbreviated definitions. 
The two entries (19) and (20) are very similar, but not identical in contents. For the inexperienced, mother-tongueoriented user, we only include collocations with the Setswana noun setulo. The version for the more advanced learners, however, jumps from setulo to chair/seat and indicates all those collocations of chair and seat which are related to the notion of piece of furniture to sit on (i.e. the meaning of setulo), even if these are more idiomatically translated without using setulo, as is the case with have a seat, please, vs. dula fatshe the (lit: 'sit down, please').

Note that collocations with readings of seat or chair which are not equivalent to setulo are not listed in either version of the entry. Collocations like win, lose, gain + seat (in an election) are only given in the receptive part of the dictionary, as no Setswana speaker would link them to setulo.

Finally, we account for the fact that setulo is underspecified with respect to hyponyms like chair/stool/bench/sofa, which is why reading (1) is subdivided into (a) to (d).

\section{Microstructure of the reception-oriented part}

Here the main objective is successful reception of the English lemma (or where necessary a multiword) i.e. understanding the meaning of the English word(s) through the Setswana equivalents. Particular attention is given to sense distinction e.g. clearly indicating the difference between chair and stool which in Setswana have the same equivalent, setulo. The Setswana microstructure can thus be fairly limited to the minimum required guidance through the mother tongue. Compare the article in (22) for the noun chair taken from (17) and covering the senses (i) piece of furniture, (ii) person in charge, (iii) position in a university and (iv) electric chair in Figure 5 above.

(22) chair noun 1 setulo, setilo, sedulo, senno; 2 modulasetulo, modulasetilo; 3 setulo sa boporofesara mo yunibesithing; 4 setulo sa motlakase (ka motlakase), thapo (ka thapo 'death by hanging')

\section{Comparison of the BLD and EBL approaches}

To make a decision on the basic approach to a final design choice, a comparison between the virtues and shortcomings of BLD and EBL dictionaries is attempted by means of comparisons regarding the macrostructures, microstructures, production, reception and translation characteristics, items 1 to 8 , of the different sections of BLD and EBL.

\begin{tabular}{|c|c|c|c|c|c|}
\hline & & \multicolumn{2}{|c|}{ BLD } & \multicolumn{2}{|c|}{ EBL } \\
\hline & & $\begin{array}{l}\text { L2-L2-L1 } \\
\text { (English lemma - English } \\
\text { definition - } \\
\text { Setswana equivalent) }\end{array}$ & $\begin{array}{l}\text { L1-L2 } \\
\text { (Setswana lemma - } \\
\text { English equivalent) }\end{array}$ & $\begin{array}{l}\text { L2-L1 } \\
\text { (English lemma } \\
\text { - Setswana } \\
\text { equivalent } \\
\end{array}$ & $\begin{array}{l}\text { L1-L2 } \\
\text { (Setswana lemma - } \\
\text { English equivalent) }\end{array}$ \\
\hline 1 & Rich macrostructure for English & YES & & YES & \\
\hline 2 & Rich macrostructure for Setswana & & $\mathrm{NO}$ & & NO \\
\hline 3 & Rich microstructure for English & YES & & NO & YES \\
\hline 4 & Rich microstructure for Setswana & NO & & NO & \\
\hline 5 & $\begin{array}{l}\text { Production of English texts and } \\
\text { speech }\end{array}$ & VERY GOOD & WEAK & WEAK & VERY GOOD \\
\hline 6 & $\begin{array}{l}\text { Translation from Setswana into } \\
\text { English }\end{array}$ & NO & WEAK & NO & VERY GOOD \\
\hline 7 & $\begin{array}{l}\text { Reception of English texts and } \\
\text { speech }\end{array}$ & VERY GOOD & NO & VERY GOOD & $\mathrm{NO}$ \\
\hline 8 & $\begin{array}{l}\text { Translation from English into } \\
\text { Setswana }\end{array}$ & WEAK & $\mathrm{NO}$ & VERY GOOD & NO \\
\hline
\end{tabular}

For item 1, both approaches offer a rich macrostructure for English, i.e. 15,000 lemmas: the BLD in the L2-L2-L1 section and the EBL in the L2-L1 section. 
The consideration for 2 is more complex: a rich macrostructure in the L1-L2 section of the BLD is impeded by the reversibility requirement of bilingualized dictionaries. This means that only those Setswana lemmas could be included as L1 for which there are reference addresses, be it lemmas or items inside the microstructures on the L2-L2-L1 side. For example modulasetulo in (16) can only be included as a lemma in the L1-L2 section since a reference address chair2 exists in the L2-L2-L1 section in (15). Should the compilers decide to accommodate all the lemmas required from the 10,000 selected Setswana tokens, extensions to the L2-L2-L1 section will have to be made to provide reference addresses for all the lemmas in the L2-L2-L1 section. This is in accordance with the reversibility principle, cf. Gouws (1989:162). Simplistically formulated, this principle suggests that all translation equivalents offered in the $\mathrm{X}$ to $\mathrm{Y}$ section of a dictionary should be lemmatized in the $\mathrm{Y}$ to $\mathrm{X}$ section.

In the case of item 3, the designs differ. In the BLD, a large part of the $80 \%$ space allocation to the L2-L2-L1 section is dedicated to the English microstructure, cf. (15). The English microstructure in the L2-L1 section of the EBL is however reduced, cf. (22). The EBL's production part, Setswana to English, has indeed a rich English microstructure, accessible via Setswana (cf. (19)).

As far as item 4 is concerned, the microstructure is limited to one or more translation equivalent(s) in both designs.

For item 5, both dictionaries score well in terms of text production: the BLD in the L2-L2-L1 section and the EBL in the L1-L2 section.

In the case of item 6, the BLD is weak since it is only usable as a translation tool from the L1-L2 index crossreferenced to the L2-L2-L1 section. The EBL in contrast, is very strong through its L1-L2 section.

As far as item 7 is concerned, both dictionaries fulfil text reception requirements, the BLD in its L2-L2-L1 section and the EBL in its L2-L1 section.

Finally, for 8, the BLD is weak as a result of the limited translation equivalent paradigm and strong for the EBL's extended L2-L1 section.

\section{Conclusions and future work}

In this article a new dictionary design for an English Setswana dictionary was attempted, considering the strong and weak points of BLDs and EBLs as basic design options. The focus was on text and speech production in the foreign language L2 (English) as well as on the text reception of English. For our purposes, an EBL will be the best option mainly in terms of

- strong guidance through the mother tongue

- strong text reception of English offered by the design of the L2-L1 section

- sufficient text production guidance in the L1-L2 section.

Our design, although bilingual in nature, shows the strong characteristics of BLDs. The imbalanced design provides for a limited macrostructure and detailed microstructure for the L1-L2 section and a large macrostructure but restricted microstructure for the L2-L1 section. We are in favour of maximum guidance through the mother tongue and believe that the advantage of guiding foreign learners through the mother tongue is an underutilized lexicographic strategy. It was also argued that it is possible to achieve a balanced dictionary even through imbalanced dictionary components, and to achieve substantial but equal coverage through unequal sizes of the lemmalists in the Setswana to English, and English to Setswana sections, i.e. unequal macrostructures that render equal coverage of over $90 \%$ of texts, for both languages. In spite of the imbalanced design, the dictionary remains balanced in terms of page allocation of 50\% for each section. Thus the goal of empowerment in English is achieved 
in both sections of the dictionary. Finally, our approach is contemplative in the sense that we considered the value and contents of dictionaries that are currently available for Setswana, and it is transformative in that it suggests alternative designs.

\section{Note}

1. Our meaning explanations are inspired by MEDAL, LDOCE and COBUILD.

\section{Appendix}

A block system for Setswana

\begin{tabular}{|c|c|c|c|c|c|c|c|c|c|}
\hline 1 & ALAF & 21 & FELE & 41 & KOUS & 61 & MOTL & 81 & SELE \\
\hline 2 & AROG & 22 & FOLO & 42 & LAEL & 62 & MPHE & 82 & SERA \\
\hline 3 & BADI & 23 & GAGW & 43 & LEBO & 63 & NATE & 83 & SETO \\
\hline 4 & BANN & 24 & GATS & 44 & LEKI & 64 & NGWA & 84 & SIMO \\
\hline 5 & BATW & 25 & GOLO & 45 & LERI & 65 & NKUK & 85 & SUAS \\
\hline 6 & BIRO & 26 & GWET & 46 & LETS & 66 & NTEM & 86 & TALE \\
\hline 7 & BOGA & 27 & HUBE & 47 & LOKO & 67 & NTSH & 87 & THAA \\
\hline 8 & BOLA & 28 & IJES & 48 & MAAD & 68 & NYOR & 88 & THIB \\
\hline 9 & BONK & 29 & IKGO & 49 & МАНА & 69 & OOMA & 89 & THWE \\
\hline 10 & BORU & 30 & INOL & 50 & MALE & 70 & PANT & 90 & TLAM \\
\hline 11 & BOUT & 31 & IPUS & 51 & MARA & 71 & PHAK & 91 & TLHA \\
\hline 12 & DAAM & 32 & ITIS & 52 & MATL & 72 & PHIM & 92 & TLHO \\
\hline 13 & DIFA & 33 & ITSH & 53 & MEFA & 73 & PITL & 93 & TLWA \\
\hline 14 & DIKG & 34 & JOKO & 54 & MESU & 74 & PUDU & 94 & TSAP \\
\hline 15 & DINK & 35 & KANY & 55 & MMAL & 75 & RAMO & 95 & TSHE \\
\hline 16 & DIRA & 36 & KERO & 56 & MMOL & 76 & RENG & 96 & TSHW \\
\hline 17 & DITH & 37 & KGAR & 57 & MOFI & 77 & ROKG & 97 & TSUN \\
\hline 18 & DITU & 38 & KGOM & 58 & MOKG & 78 & RURU & 98 & UBAU \\
\hline 19 & EGEP & 39 & KHAN & 59 & MONG & 79 & SEBA & 99 & WABO \\
\hline 20 & ETLH & 40 & KODU & 60 & MORW & 80 & SEHI & 100 & ZIMB \\
\hline
\end{tabular}

\section{References}

\section{Dictionaries}

(CMSAD) 1996. Chambers-Macmillan South African dictionary senior primary. Manzini: Macmillan Boleswa. (COBUILD) Sinclair, J. (ed.). 1988. Collins COBUILD English language dictionary. London: Harper Collins.

(DS) Snyman, J.W., Shole, J.S. \& Le Roux J.C. 1990. Dikišinare ya Setswana English Afrikaans dictionary.

Woordeboek. Pretoria: Via Afrika Limited.

(LDOCE) http://www.ldoceonline.com

(MED) 2007. Rundell, M. (ed.). Macmillan English dictionary for advanced learners. Second edition 2007 on

CD-ROM. A\&C Black Publishers Ltd. 
(MEDAL) 2007. Rundell, M. (ed.). Macmillan English dictionary for advanced learners. Second edition 2007. Macmillan.

(MWB) http://www.mijnwoordenboek.nl

(ONSD) De Schryver, G-M. (ed.). 2007. Oxford bilingual school dictionary: Northern Sotho and English. (First edition). Cape Town: OUP Southern Africa.

(SED) Brown, J. Tom. 1946. Secwana-English Dictionary. Vryburg: South African District Committee of the London Missionary Society.

(SESD) Matumo, Z.I. 1993. Setswana-English-Setswana dictionary. Gaborone: Macmillan.

\section{Other Literature}

Adamska-Sałaciak, Arleta. 2006. Meaning and the bilingual dictionary. The case of Polish and English. Frankfurt am Main: Peter Lang.

Adeyemi, Deborah A. 2008. Bilingual education: Meeting the challenges of diversity in Botswana. Nordic Journal of African Studies 17(1):20-33.

Atkins, B.T.S. 1985. Monolingual and bilingual learners' dictionaries: A comparison, in Dictionaries, lexicography and language learning (ELT Documents 120), edited by R. Ilson. Oxford: Pergamon Press and the British Council:15-24.

Atkins, B.T.S. 1992/3. Theoretical lexicography and its relation to dictionary making, in Journal of the Dictionary Society of North America, edited by W. Frawley, 14:4-43.

Atkins, B.T. Sue \& Rundell, Michael. 2008. The Oxford guide to practical lexicography. Oxford, New York: Oxford University Press.

Atkins, Sue \& Grundy, Valerie. 2006. Lexicographic profiling: An aid to consistency in dictionary entry design, in Proceedings of the 12th EURALEX International Congress on Lexicography, edited by E. Corino, C. Marello \& C. Onesti. University of Turin, Italy, 6-9 September 2006, E.:1097-1107.

Atkins, B.T.S. \& Varantola, K. 1997. Monitoring dictionary use. IJL 10(1):1-45.

Aust, R., Kelley, M.J. \& Roby, W. 1993. The use of hyper-reference and conventional dictionaries. Educational Technology Research and Development 41:63-73.

Barnhart, C.L. 1962. Problems in editing commercial monolingual dictionaries, in Problems in lexicography, edited by F.W. Householder \& S. Saporta. Bloomington: Indiana University:161-181.

Bergenholtz, H. \& Tarp, S. 2002. Die moderne lexikographische Funktionslehre. Diskussionsbeitrag zu neuen und alten Paradigmen, die Wörterbücher als Gebrauchsgegenstände verstehen. Lexicographica 18:253-263.

Bogaards, P. \& Hannay, M. 2004. 'Towards a new type of bilingual dictionary', in Proceedings of the 11th EURALEX International Conference, edited by G. Williams \& S. Vessier. Lorient, Universite de BretagneSud:463-474.

Convery, Cathal, Ó Mianáin, Pádraig, Ó Raghallaigh, Muiris, Atkins, Sue, Kilgarriff, Adam \& Rundell, Michael. The DANTE Database (Database of ANalysed Texts of English). Proceedings of the 14th EURALEX International Congress on Lexicography, Leeuwarden, 6-10 July 2010:293-295.

Gouws, R.H. 1989. Leksikografie. Cape Town: Academica.

Gouws, R.H. \& Prinsloo, D.J. 2005. Principles and practice of South African lexicography. Stellenbosch: African Sun Media.

Haas, M.R. 1962. What belongs in the bilingual dictionary? in Problems in lexicography, edited by F.W. Householder \& S. Saporta. Bloomington: Indiana University:45-50.

Hausmann, Franz Josef. 1977. Einführung in die Benutzung der neufranzösischen Wörterbücher. Tübingen: Niemeyer.

Kaalep, Heiki-Jaan \& Mikk, Jaan. 2008. Creating specialised dictionaries for foreign language learners: A case study. International Journal of Lexicography 21(4):369-394. 
Kernerman, Lionel. 2000. Pedagogic lexicography: Some recent advances and some questions about the future. Proceedings of the Ninth EURALEX International Congress on Lexicography, Stuttgart, 8-12 August 2000:825-829.

Kilgarriff, A., Rychly, P., Smrz, P. \& Tugwell, D. 2004. 'The sketch engine', in Proceedings of the Eleventh EURALEX International Congress, edited by G. Williams \& S. Vessier. EURALEX 2004, Lorient, France, July 6-10, 2004:105-116.

Laufer, Batia \& Levitzky-Aviad, Tamar. 2006. Examining the effectiveness of 'Bilingual dictionary plus' - A dictionary for production in a foreign language. International Journal of Lexicography 19(2):135-155.

Marello, C. 1989. Dizionari bilingui con schede sui dizionari italiani per francese, inglese, spagnolo, tedesco. Bologna: Zanichelli.

Marello, Carla. 1998. Hornby's bilingualized dictionaries. IJL 11(4):292-314.

Nakamoto, K. 1994. Monolingual or bilingual, that is not the question: The 'bilingualised' dictionary. Iwasaki Linguistic Circle. Tokyo, Japan.

Otto, A.N. 1989. Kriteria vir 'n Afrikaanse aanleerderwoordeboek. Unpublished doctoral thesis. Stellenbosch: University of Stellenbosch.

Piotrowski, T. 1989. Monolingual and bilingual dictionaries: Fundamental differences, in Learners' dictionaries: State of the art, edited by M.L. Tickoo. SEAMEO RELC, Singapore:72-83.

Prinsloo, D.J. 2004. Revising Matumo's Setswana - English - Setswana Dictionary. Lexikos 14:158-172.

Prinsloo, D.J. 2006. Compiling a bidirectional dictionary bridging English and the Sotho languages: A viability study. Lexikos 16:193-204.

Prinsloo, D.J. \& De Schryver, G-M. 2002. Designing a measurement instrument for the relative length of alphabetical stretches in dictionaries, with special reference to Afrikaans and English, in Proceedings of the Tenth EURALEX International Congress, edited by A. Braasch \& A. and C. Povlsen. EURALEX 2002, Copenhagen, Denmark, August 13-17, 2002:483-494. Copenhagen: Center for Sprogteknologi, Københavns Universitet.

Prinsloo, D.J. \& De Schryver, G-M. 2003. Effektiewe vordering met die Woordeboek van die Afrikaanse taal soos gemeet in terme van 'n multidimensionele liniaal [Effective progress with the Woordeboek van die Afrikaanse taal as measured in terms of a multidimensional ruler], in 'n Man wat beur. Huldigingsbundel vir Dirk van Schalkwyk, edited by W.F. Botha. Stellenbosch: Buro van die WAT:106-126.

Prinsloo, D.J. \& De Schryver, G-M. 2005. Managing eleven parallel corpora and the extraction of data in all official South African languages, in Multilingualism and electronic language management (Studies in Language Policy in South Africa 4), edited by W. Daelemans, T. du Plessis, C. Snyman \& L. Teck. Pretoria: J.L. van Schaik:100-122.

Prinsloo, D.J. \& Gouws, R.H. 1996. Formulating a new dictionary convention for the lemmatization of verbs in Northern Sotho. South African Journal of African Languages 16(3):100-107.

Pujol, Didac, Corrius, Montse \& Masnou, Joan. 2006. Print deferred bilingualised dictionaries and their implications for effective language learning: A new approach to pedagogical lexicography. International Journal of Lexicography 19(2):197-215.

Rundell, M. 2008. Recent trends in English pedagogical lexicography, in Practical lexicography. A reader, edited by Thierry Fontenelle. New York: Oxford University Press Inc.:221- 244.

Sketch Engine (http://www.sketchengine.co.uk/)

Tarp, Sven. 2008. Lexicography in the borderland between knowledge and non-knowledge. Lexicographica Series Maior. Tübingen: Max Niemeyer Verlag.

Thumb, Yin Fun Jenny. 2002. Dictionary look-up strategies and the bilingualised learner's dictionary: A thinkaloud study. Unpublished doctoral thesis. Hong Kong: University of Hong Kong.

Tomaszczyk, J. 1983. On bilingual dictionaries: The case of bilingual dictionaries for foreign language learners, in Lexicography: Principles and practice, edited by R.R.K. Hartmann. London: Academic Press:41-45. 